\title{
Organization of blood oxygen transport system for cottoid fishes of Lake Baikal
}

\author{
Yakhnenko V.M.*, Klimenkov I.V., Sudakov N.P., Kirilchik S.V., Nebesnykh I.A., \\ Khanaev I.V.
}

Limnological Institute, Siberian Branch of the Russian Academy of Sciences, Ulan-Batorskaya Str., 3, Irkutsk, 664033, Russia

\begin{abstract}
The blood of cottoid fishes has the lowest parameters that characterize the ability of heamoglobin to bind oxygen. Environmental characteristics of the species determine the morphological parameters of red blood cells and the structure of haemoglobins. In red blood cells of the Baikal yellowfin sculpin under the exposure of phenol, we revealed the damage of intracellular structures and a decrease in the number of active mitochondria by $60 \%$.
\end{abstract}

Keywords: cottoid fish, Lake Baikal, ecological group, red blood cells, haemoglobins

Red blood cells (RBC) and haemoglobin ( $\mathrm{Hb}$ ) protein are the main chain in the system of oxygen transport in fish. The composition and morphology of $\mathrm{RBC}$ in fish are genetically determined and speciesspecific. Morphological parameters of RBC are variables that correlate with all aspects of the body's vital activity, characteristics of habitat and its changes (Yakhnenko et al., 2016; Lahnsteiner, 2020). However, little is known about the role of various factors and the degree of their impact on the blood system in fish. This is relevant for cottoid fishes of Lake Baikal.

This study aims to assess the quantitative and qualitative features of RBC as well as the structure of haemoglobins in members of cottoid fishes from Lake Baikal belonging to different ecological groups.

\section{Materials and methods}

The peripheral blood from 17 sculpin fish species (Cottoidei) was studied. In the family Cottidae, there were benthopelagic species of the genus Cottocomephorus, bentho-coastal species of the genera Paracottus and Leocottus, benthic abyssal species of the genus Procottus, bentho-coastal, bathypelagic and benthic abyssal species of the genus Batrachocottus. In the family Comephoridae, there were pelagic species of the genus Comephorus, and in the family Abyssocottidae - benthic abyssal species of the genera Abyssocottus Asprocottus and Limnocottus.

Standard procedures of hematologic (Yakhnenko et al., 2016) and ultrastructural (Weakley, 1975) analysis were used. Erythrocyte size was measured using Image Pro Plus 6.0 computer software. Studies of the $\mathrm{Hb}$ structure were carried out using the isoelectric focusing method (Righetti, 1983). The experiments were carried out on the effect of phenol (concentration $3 \mathrm{mg} / 1$, control, 24 hours, and four days of exposure) on the blood parameters and the structure of RBC of the Baikal yellowfin sculpin.

\section{Results}

The peripheral blood of the studied fishes had mature RBC (up to 90\%) and erythroblasts (immature forms of RBC). In the cytoplasm of mature RBC, we detected ribosomes, endoplasmic reticulum and mitochondria. In comparison with other Baikal fishes, the blood of cottoid fishes has the lowest $\mathrm{Hb}$ concentration as ell as the lowest parameters of the number of RBC per unit of blood volume, oxygen carrying capacity of blood and the $\mathrm{Hb}$ concentration in RBC (Yakhnenko et al., 2016). Bentho-coastal species and pelagic species, except for golomyankas, have the highest RBC concentration, and ellipsoid degree of RBC, and benthic abyssal species - the lowest one. Abyssal fishes have the highest cytometric parameters of $\mathrm{RBC}$ and their nuclei. $\mathrm{Hb}$ in golomyankas is reliably higher, but the erythropoiesis level is lower compared to other pelagic species. In contrast to big golomyanka, $\mathrm{RBC}$ in small golomyanka are larger, and the ellipsoid degree is lower.

In coastal pelagic species, cathodic fractions prevail in the $\mathrm{Hb}$ structure. Abyssal species and golomyankas have both cathodic and anodic fractions, which at low temperatures allows $\mathrm{Hb}$ to bind with a high degree of saturation.

Experiments on the effect of phenol on the composition and structure of blood cells of the Baikal

*Corresponding author.

E-mail address: vera@lin.irk.ru (V.M. Yakhnenko) 
yellowfin sculpin have revealed that, in addition to the damage of intracellular structures, vacuolization of mitochondria and damage to mitochondrial cristae, the number of active mitochondria decreases by $60 \%$.

Therefore, at present, we have not revealed any deteriorations in the structure and morphology of RBC in the Baikal cottoid fishes from different ecological groups.

\section{Acknowledgements}

This work was performed at the Shared Research Facilities for Physical and Chemical Ultramicroanalysis (http://www.lin.irk.ru/copp/eng/) and the Large-Scale Research Facilities "Experimental Freshwater Aquarium Complex for Baikal Hydrobionts" of LIN SB RAS (http://www.lin.irk.ru/aqua), supported by Russian Foundation for Basic Research and the Government of the Irkutsk region, projects No. 17-44-388081 r_a and No. 17-44-388106 r_a, and performed within the framework of the state task No. 0345-2019-0002 (AAAA-A16-116122110066-1) "Molecular ecology and evolution of living systems...".

\section{References}

Lahnsteiner F. 2020. Erythrocyte morphometry in teleost fish - Species-specific, inter-individual and environmentalrelated differences. Acta Zoologica 2020: 1-13. DOI: 10.1111/ azo. 12330

Righetti P.G. 1983. Isoelectric focusing: theory, methodology and applications. Amsterdam: Elsevier.

Weakley B.S. 1975. A beginner's handbook in biological electron microscopy. Edinburgh: Churchill Livingstone.

Yakhnenko V.M., Klimenkov I.V., Sudakov N.P. et al. 2016. Morphofunctional peculiarities of erythrocytes in wild and farmed coregonid fishes from Lake Baikal. Contemporary Problems of Ecology 9(2): 219-228. DOI: 10.1134/ S1995425516020116 